\title{
Pattern of adverse drug reactions to antibiotics commonly prescribed in department of medicineand pediatrics in a tertiary careteaching hospital, Ghaziabad
}

\author{
Kavita Dhar ${ }^{*}$, Akanksha Sinha ${ }^{2}$, Preeti Gaur ${ }^{1}$, Rajkumar Goel ${ }^{1}$, V.S Chopra ${ }^{1}$, Umakant Bajaj ${ }^{2}$ \\ ${ }^{1}$ Department of Pharmacology, Santosh Medical College and Hospitals, Santosh University, Ghaziabad, India. \\ ${ }^{2}$ Krishna Institute of Engineering \& Technology, Ghaziabad, India.
}

\section{ARTICLE INFO \\ Article history: \\ Received on: $27 / 11 / 2014$ \\ Revised on: 09/01/2015 \\ Accepted on: 14/02/2015 \\ Available online: 27/04/2015}

Key words:

Adverse drug reaction

(ADR), Antibiotics, Beta-

Lactams, Pharmacovigilance, WHO Scale.

\begin{abstract}
Adverse Drug Reactions (ADRs) are an important cause of mortality and morbidity and constitute an enormous burden on the society. Many studies have implicated that the antibiotics are among the major group of drugs, which cause adverse drug reactions (ADRs). This Retrospective, non- interventional study was undertaken in Medicine and Pediatrics unit from November 2013 to April 2014 to monitor the adverse drug reactions of antibiotics prescribed by physicians and pediatricians in a tertiary care hospital, Ghaziabad, to establish ten most common antibiotics which caused ADRs, to determine most commonly affected organ system and assess their causality. A total of 126 ADRs were identified in 80 patients, out of which $42(52.5 \%)$ occurred in male patients and $38(47.5 \%)$ in female patients. The age wise distribution revealed that adult patients showed more incidence of ADRs 46(57.5\%), followed by children 26(32.5\%) and Geriatrics 8(10\%). GIT 28(22.2\%) was the most affected organ system by Adverse Drug Reactions due to antibiotics followed by the Respiratory system 26 (20.63\%), Skin 23(18.25\%), CVS 17 (13.5\%), CNS 12(9.52\%), Musculo-skeletal system 10(7.93\%), Urinary System 8 (6.35\%) and Haemopoietic Disorders 2 (1.58\%). Maximum ADRs were reported with Beta-Lactams class $51(40.4 \%)$ followed by Aminoglycosides 29(23.01\%), Quinolones 20(15.8\%), Others $16(12.69 \%)$ and Macrolides $10(7.93 \%)$, . Antibiotics comprise the major volume of the drug family and inpatient prescriptions and thus are the most irrationally prescribed. So implementation of antibiotic guideline policy for the hospitals and strict adherence to it should be ensured to promote their rational and safe use. Also health system needs to promote spontaneous reporting of ADRs detected in clinical practice to Regional Pharmacovigilance centers.
\end{abstract}

\section{INTRODUCTION}

Drugs are the commonest medical interventions, used to relieve sufferings but drugs themselves can prove fatal and result in ADR; as the saying rightly goes "Drugs are Double Edged Weapons" (Phatak and Nagari, 2003). Since new drugs are being introduced every year, hence need for an active surveillance system. This is the basis for starting the international drug monitoring program by the WHO (Surendiran et al., 2010).

* Corresponding Author

Email:dhar.kavita12@gnail.com
WHO defines ADR as "any response to a drug which is noxious and unintended, and occurs at doses normally used in man for prophylaxis, diagnosis or therapy of disease, or for the modification of physiologic function". Adverse Drug Reactions (ADRs) are important causes of mortality and morbidity. Early detection, evaluation, monitoring and reporting of ADR are essential to make drug treatment safe, efficacious and cost effective (PirMohamed and Brecken, 1998). According to a study (Novotny \& Novotny, 1999) the most troublesome classes of drugs contributing to Adverse Drug Reactions were antibiotics followed by Anticancer drugs. 
Antibiotics are currently the most commonly prescribed drugs in hospitals, worldwide (Faryna et al., 1987). But, excessive and inappropriate use of antibiotics renders its major limitation i.e, increased drug resistance (Park, 2012). Antibiotic Resistance occurs when an antibiotic is no longer effective at killing or limiting the growth of bacteria. The rational use of antibiotics is a major health need. Prevention of ADRs is possible by proper monitoring, which fortified the national directive to institutionalize a pharmacovigilance center in every medical college in the country (Chakraborthy \& Thawani, 2011). It is extremely important that institutions and hospitals have an antibiotic policy and ensure that the best choices are made by individual prescribers.

Over half of all hospitalized patients are treated with antimicrobial agents and their use account for $20-50 \%$ of drug expenditures in hospitals. The total costs associated with antibiotics are not only related to antibiotic use itself, but also adverse drug events.

The incidence and severity of ADRs can be influenced by patient- related factors like age, sex, concurrent diseases, genetic factors, and drug related factors like type of drug, route of administration, duration of therapy, and dosage. The other important risk factors associated with adverse drug reactions are gender, increased number of drug exposures, advanced age, length of hospital stay and function of excreting organs (Beard and Lee, 2001). Health care professionals-doctors, dentists, pharmacists, nurses are the most preferred source of data collection related to ADRs. Antibiotics are grouped on basis of mechanism of action or chemical structure as Penicillins, Cephalosporins, Sulfonamides, and Aminoglycosides.

Main aim of the study was to monitor the safety (adverse drug reactions) of antibiotics commonly prescribed in medicine and pediatricss unit of tertiary care teaching hospital, Ghaziabad for a period of 6 months, establish most common antibiotics that give maximum ADRs, determine the list of most commonly affected organ system and assess the causality of ADRs.

\section{MATERIALS AND METHODS}

This Retrospective, Observational, non-interventional study was carried out in the Department of Medicine and Pediatrics in a 700-bedded tertiary care teaching hospital, U.P, India. ADRs with antibiotics were reported from November 2013 to April 2014 and analyzed using Microsoft Excel. High incidence of Antibiotics prescription and associated ADRs were observed (Fonacier et al., 2005).

All patients of either sex and of any age who developed ADR were included in the study. The patients with complications, severe and terminally ill patients and emergency patients were excluded from the study. Patient case notes/files and CDSCO (suspected ADR) forms were used as main sources of data collection besides consultation with prescribing doctors. The protocol of the study was approved by the Research and Bioethical Committee of the hospital and final permission was sought from Indian Pharmacopeia Commission (IPC-NCC-PvPI) which functions as National Co-ordination Centre for PvPI before commencement of study.

\section{RESULTS AND OBSERVATIONS}

A total of 126 ADRs were collected, tabulated in CDSCO forms, analyzed and assessed on WHO causality assessment scale. The data collected during the six month period was analyzed for the total number of ADRs reported, different organ systems affected by the reactions, classification of drugs causing reactions. Study revealed that male patients $42(52.5 \%)$ predominated over females 38 (47.5\%) in ADR occurrence [Fig. 1]. The age wise distribution of ADRs revealed adults patients accounted $46(57.5 \%)$, followed by children $26(32.5 \%)$ and Geriatrics 8(10\%) [ Fig. 2].

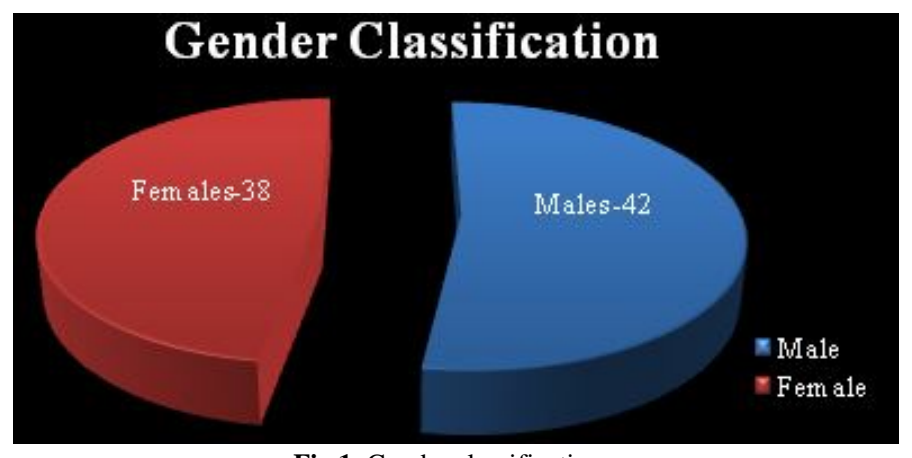

Fig 1: Gender classification.

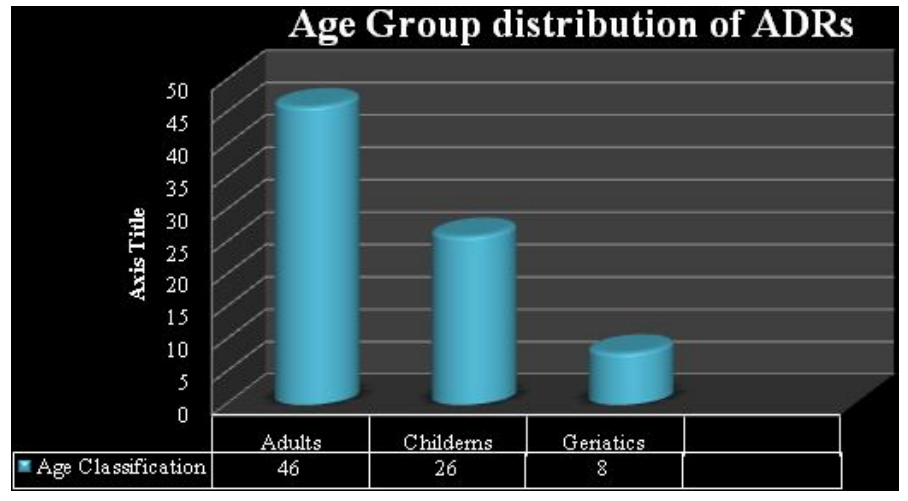

Fig 2: Age group distribution of ADRs.

GIT 28(22.2\%) was the most affected organ system by Adverse Drug Reactions due to antibiotics followed by the Respiratory system 26 (20.63\%), Skin 23(18.25\%), CVS 17 (13.5\%), CNS 12(9.52\%), Musculo-skeletal system 10(7.93\%), Urinary System 8 $(6.35 \%)$ and Haemopoietic Disorders 2 (1.58\%).[Table 1]

Maximum ADRs were reported with Beta-Lactams (Ceftriaxone, Amoxicillin/Clavulanic acid, Cefotaxim, Tazobactam) 51 (40.4\%) followed by Quinolones (Ofloxacin, Levofloxacin) 20(15.8\%), Macrolides (Azithromycin) 10(7.93\%), Aminoglycosides (Amikacin, Streptomycin, 29(23.01\%), and Metronidazole \& others 16 (12.69\%).

[Figure 3] [Table 2]

The most common ADR was Abdominal pain 16(12.7\%), Dyspnoea, Nausea \& Vomiting, Cough 12(9.52\%), 
Diarrhoea $11(8.75 \%)$, Headache 10(7.9\%), Fatigue $7(5.55 \%)$, Vertigo 6 (4.7\%), Pain in multiple joints, Rashes 5 (3.96\%), Tingling sensation, Bodyache $4(3.17 \%)$, Constipation, Itching and inflammatory swelling, Anxiety, Throat pain $3(2.38 \%)$, Restlessness, Change in stool color 2 (1.58\%), Tinnitus, Hallucination, Nocturia, Pedal Oedema, Nasal blockage, Oral Ulcers $1(0.8 \%)$. [Table 3]

Table 1: Organ-system affected Due To ADR $(n=126)$

\begin{tabular}{clcc}
\hline $\begin{array}{c}\text { Sr. } \\
\text { No. }\end{array}$ & \multicolumn{1}{c}{ Organ Systems Affected } & $\begin{array}{c}\text { No. Of } \\
\text { Adr }\end{array}$ & $\begin{array}{c}\text { \% Of } \\
\text { Adr }\end{array}$ \\
\hline 1 & Urinary system disorder & 8 & 6.35 \\
2 & Gastro-intestinal system disorder & 28 & 22.2 \\
3 & Respiratory System disorder & 26 & 20.63 \\
4 & Skin and Appendages disorder & 23 & 18.25 \\
5 & Central and Peripheral system disorder & 12 & 9.52 \\
6 & Cardiovascular system disorder & 17 & 13.5 \\
7 & Musculo-skeletal system disorder & 10 & 7.93 \\
8 & Haemopoetic disorder & 2 & 1.58 \\
\hline \multicolumn{4}{c}{ Total } \\
\hline
\end{tabular}

\section{Most common 10 Antibiotics that give maximum ADRs}

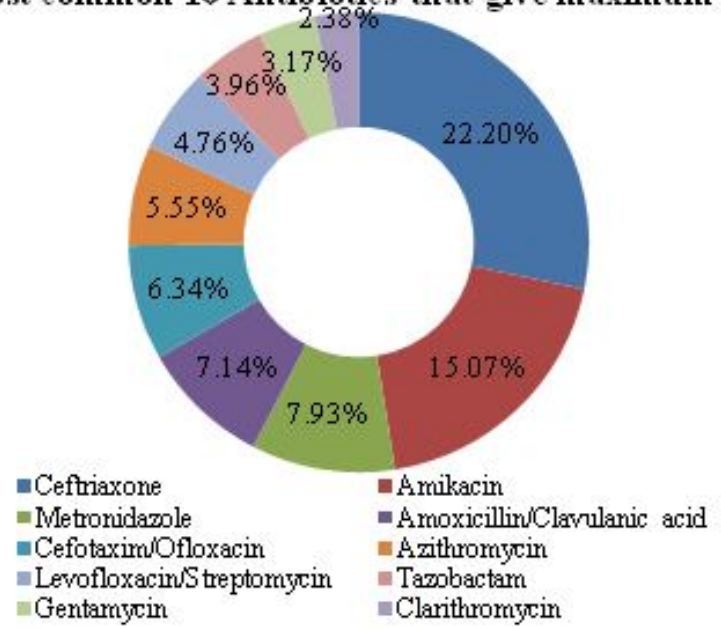

Fig 3: Most common 10 antibiotics that give maximum ADRs.

\section{Causality Assessment}

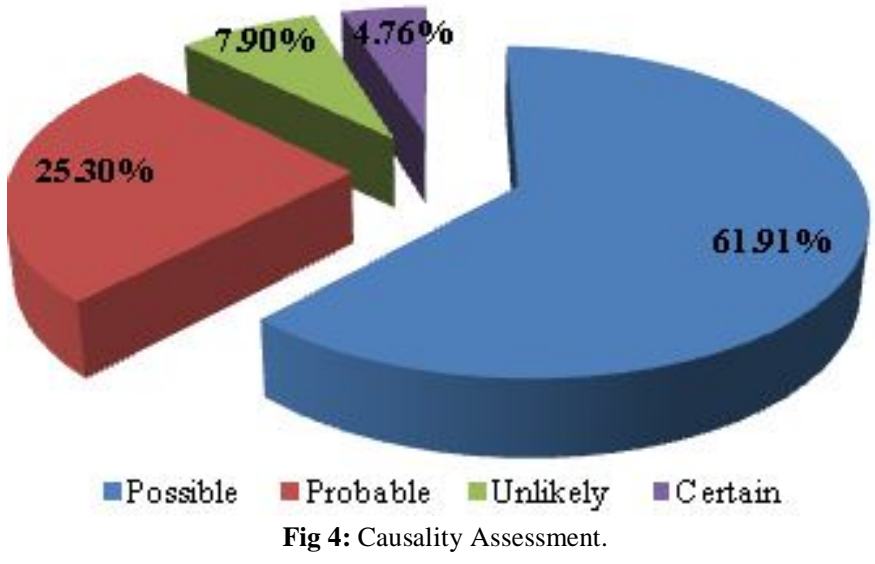

The assessment by WHO causality assessment scale showed that out of 126 ADRs, $6(4.76 \%)$ were certain, $78(61.9 \%)$ were possible, $32(25.3 \%)$ were probable and $10(7.9 \%)$ were unlikely.[Figure 4] [Table 4] Whenever the patient had severe
ADR to the particular drug, 'ADR alert card ' was given to the patient, and they were asked to produce the same, while visiting the physician or pharmacist in their follow-up.

Table 2: Therapeutic Class of Antibiotic s Implicated to Cause ADR ( $\mathrm{n}=126)$.

\begin{tabular}{|c|c|c|c|c|}
\hline $\begin{array}{l}\text { Sr. } \\
\text { No. }\end{array}$ & Class of Drug & Name of Drug & $\begin{array}{l}\text { No. of } \\
\text { ADR }\end{array}$ & $\begin{array}{l}\text { \% of } \\
\text { ADR }\end{array}$ \\
\hline \multirow{5}{*}{1} & \multirow{5}{*}{ Beta-Lactams } & Ceftriaxone & 28 & $22.2 \%$ \\
\hline & & Cefotaxim & 8 & $6.34 \%$ \\
\hline & & Piperacillin/Tazobactum & 5 & $3.96 \%$ \\
\hline & & $\begin{array}{l}\text { Amoxicillin/Clavulanic } \\
\text { Acid }\end{array}$ & 9 & $7.14 \%$ \\
\hline & & Cefoperazone & 1 & $0.79 \%$ \\
\hline \multirow{3}{*}{2} & \multirow{3}{*}{ Quinolones } & Ofloxacin & 8 & $6.34 \%$ \\
\hline & & Ciprofloxacin & 6 & $4.76 \%$ \\
\hline & & Levofloxacin & 6 & $4.76 \%$ \\
\hline \multirow{2}{*}{3} & \multirow{2}{*}{ Macrolides } & Azithromycin & 7 & $5.55 \%$ \\
\hline & & Clarithromycin & 3 & $2.38 \%$ \\
\hline \multirow{3}{*}{4} & \multirow{3}{*}{$\begin{array}{l}\text { Aminoglycoside } \\
\mathrm{s}\end{array}$} & Amikacin & 19 & $15.07 \%$ \\
\hline & & Gentamycin & 4 & $3.17 \%$ \\
\hline & & Streptomycin & 6 & $4.76 \%$ \\
\hline \multirow{6}{*}{5} & \multirow{6}{*}{ Miscellaneous } & Linezolid & 2 & $1.58 \%$ \\
\hline & & Doxycycline & 1 & $0.79 \%$ \\
\hline & & Rifaximin & 2 & $1.58 \%$ \\
\hline & & Clindamycin & 1 & $0.79 \%$ \\
\hline & & Metronidazole & 10 & $7.93 \%$ \\
\hline & & Total & 126 & \\
\hline
\end{tabular}

Table 3: Types Of Reactions Observed $(n=126)$

\begin{tabular}{|c|c|c|c|}
\hline $\begin{array}{l}\text { SR. } \\
\text { No. }\end{array}$ & Types of Reactions & $\begin{array}{l}\text { No. of } \\
\text { ADRs }\end{array}$ & $\begin{array}{l}\% \text { of } \\
\text { ADR }\end{array}$ \\
\hline 1. & Abdominal pain & 16 & 12.7 \\
\hline 2. & Vertigo & 6 & 4.7 \\
\hline 3. & Pedal Oedema & 1 & 0.79 \\
\hline 4. & Dyspnoea & 12 & 9.52 \\
\hline 5. & Restlessness & 2 & 1.58 \\
\hline 6. & Cough & 12 & 9.52 \\
\hline 7. & Fatigue & 7 & 5.55 \\
\hline 8. & Oral Ulcers & 1 & 0.8 \\
\hline 9. & Throat pain & 3 & 2.38 \\
\hline 10. & Nausea \& Vomiting & 12 & 9.52 \\
\hline 11. & Tingling sensation & 4 & 3.17 \\
\hline 12. & Pain in multiple joint & 5 & 3.96 \\
\hline 13. & Anxiety & 3 & 2.38 \\
\hline 14. & Rashes & 5 & 3.96 \\
\hline 15. & Diarrhoea & 11 & 8.75 \\
\hline 16. & Change in stool colour & 16 & 1.58 \\
\hline 17. & Bodyache & 4 & 3.17 \\
\hline 18. & Headache & 10 & 7.9 \\
\hline 19. & Nasal blockage & 1 & 0.79 \\
\hline 20. & Constipation & 3 & 2.38 \\
\hline 21. & Itching and inflammatory swelling & 3 & 2.3 \\
\hline 22. & Tinnitus & 1 & 0.8 \\
\hline 23. & Hallucination visual & 1 & 0.8 \\
\hline \multirow[t]{2}{*}{24.} & Nocturia & 1 & 0.8 \\
\hline & Total & 126 & \\
\hline
\end{tabular}

Table 4: WHO Causality Assessment of ADRs ( $n=126)$.

\begin{tabular}{clccc} 
S. No. & \multicolumn{1}{c}{ Type Of Reactions } & $\begin{array}{c}\text { No. of } \\
\text { ADRs }\end{array}$ & Percentage \\
\hline 1. & Certain & 6 & 4.76 \\
2. & Possible & 78 & 61.9 \\
3. & Probable/Likely & 32 & 25.3 \\
4. & Unlikely & 10 & 7.9 \\
$\mathbf{5 .}$ & Unassessible/Unclassifiable & 0 & 0 \\
6. & Conditional/Unclassified & 0 & 0 \\
\hline & Total & 126 \\
\hline
\end{tabular}




\section{DISCUSSION}

Most infections, including the infections of nosocomial origin, are serious in nature and require longer and complex treatment procedures. Their therapy always includes antibiotics. As the drug resistance incidence is on the raise, there is a huge need for taking steps to promote rational use of antibiotics. Antibiotics are the most commonly used and misused drugs by patients and prescribers (Fonacier et al., 2005).

Antibiotics are used for treatment and prophylaxis of various infectious conditions and are considered as safer drugs when used rationally. But, as with other drugs, they too show Adverse Drug Reactions. This study tried to find out the pattern of Adverse Drug Reactions of antibiotic drug class in the post marketing surveillance studies to find out the effects in a large and diverse population. In the studies carried out in Nigerian children antibiotics were the most accounted drug class in ADR occurrence and they were the second most accounted in another study (Chambers, 2006; Oshikoya et al., 2007; Misbah et al., 2010). Antibiotics are considered as the second most prescribed drugs in the world, only next to the drugs indicated for cardiovascular diseases (Tunger et al., 2000).

The predominance of male sex for ADRs with antibiotics may be due to majority of the admitted patients were male with more antibiotic use during the study period. Analysis of the age wise distribution (Jose et al., 2008; Suthar et al., 2011) showed the predominance of adult patients followed by children and this result implied that the adults patients were more prone to antibiotic Adverse Drug Reactions due to age related pharmacokinetic and pharmacodynamic changes and the presence of co-morbid illnesses and multiple drugs along with infectious diseases. Another study also showed the male predominance and the age group most accounted were adults in both the studies (Stavreva et al., 2008) .

High antibiotic ADRs were detected in Medicine and Pediatrics departments and may be due to frequent prescription of antibiotics in these units. Gastro-intestinal tract was the main organ system affected followed by Respiratory and Cutaneous manifestations. Other studies also found the predominance of the gastrointestinal system (Horen et al., 2002; Bera et al., 2002) followed by the skin (Oshikoya et al., 2007; Misbah et al., 2010) in ADR occurrence.

The cephalosporins were the most used antibiotic class, as shown by another study (Misbah et al., 2010) also which revealed the predominance of Cephalosporins, Vancomycin and Penicillins (Chambers et al., 2006). The analysis of the fate of the suspected drugs showed that the drug was withdrawn in many of the cases and the dose altered in some while no change was made in others keeping the risk benefit ratio consideration .In some cases the use of antibiotic was according to the culture and sensitivity reports. Drug rechallenge was not done in any of the cases. Some of the healthcare providers were not much aware of the importance of reporting and follow up of those reactions and they were not willing to change the drug or alter the dose. Vast majority of the patients recovered from ADR because none of the reported reactions were fatal (Available at http://www.WHOUMC.org/graphics/4409.pdf, Accessed on 04 November, 2014). It was also found that moderate and mild reactions were more but some severe reactions were also reported.

\section{CONCLUSION}

Of the 80 patients analyzed over a period of six months, it was observed that the hospital physicians prescribed antibiotics rationally, no banned drugs per CDSCO and less newer drugs were prescribed.

Antibiotics comprise the major volume of the drug family and inpatient prescriptions and thus are the most irrationally prescribed drug class. So implementation of antibiotic guidelines for the hospital scenario and strict adherence should be ensured to promote their rational use. The health system should promote the spontaneous detection of the Adverse Drug Reactions and delivering the awareness classes for the healthcare professionals regarding the need for reporting the incidents, incorporating ADR information in patient charts to improve the scenario in under-reported hospitals. Reporting of Adverse Drug Reactions to antibiotics and other drugs, proper documentation and periodic reporting to regional pharmacovigilance centers will ensure Antibiotics safety (Dhar et al., 2014). A constraint was the non-usage of computerized system of documentations by prescribers in the hospital. A periodic survey with increased number of subjects is needed for implementation of antibiotic policies.

Healthcare Professionals have an important responsibility in monitoring the ongoing safety of medicines. The incidence of adverse drug events is not directly proportional to the number of drugs being taken but increases remarkably as number of drugs rises. Poly-pharmacy needs to be discouraged for a good number of ADRs results from drug-drug interaction. Early signals of irrational use of drugs can be detected by frequent prescription auditing. This should be followed by analytical studies to link the drug utilization data to figures on morbidity, outcome of treatment, quality of care, and ultimately assess the rationality of drug therapy.

Pharmacovigilance needs to be enforced in our country for better and safe use of drugs. Our ability to anticipate and present ADRs can be facilitated by the establishment of standardized approaches . Although it would be prudent to initially focus on the more serious ADRs, yet it is important to consider even so called non- serious ADRs as they can have a significant impact on the patient's quality of life.

\section{REFERENCES}

Abimanyu Phatak, B.G. Nagari .Safety of medicines. Pharma Times, 2003; 35: 19-21.

A. Surendiran, N. Balamurugan, K. Gunaseelan, Shahid Akhtar, K.S. Reddy, C. Adithan Adverse drug reaction profile of cisplatin-based chemotherapy regimen in a tertiary care hospital in India: an evaluative study. Indian J. Pharmacol., 2010; 42 (1): 42-43 
Beard, K., Lee, A. 2001. Eds. Adverse Drug Reactions.1st Edn., Pharmaceutical Press, London.

Chambers HF. General Principles of antimicrobial therapy. In: Brunton LL, Lazo JS, Parker KL. 2006. Eds. Goodman and Gillman's The pharmacological basis of therapeutics. 11 th ed. New York: Mc Graw-Hill Press. p. 1095-110.

Chakraborthy M, Thawani V. Starting a Pharmacovigilance Centre: Actions for Implementation. J Pharmacol Pharmacother 2011; 2:295-9.

Faryna A, Gilbert L. Wergowske, Kim Goldenberg. Impact of therapeutic guidelines on antibiotic use by residents in primary care clinics. J Gen Intern Med, 1987;2:102-7.

Fonacier L, Hirschberg R, Gerson S. Adverse drug reactions to cephalosporins in hospitalized patients with a history of penicillin allergy. Allergy Asthma Proc. 2005;26: 135-41

G. Stavreva, D. Pendicheva, A. Pandurska, R. Marev. Detection of adverse drug reactions to antimicrobial drugs in hospitalized patients. Trakia J. Sci., 2008; 6 (1): 7-9.

Horen B, Montastruc JL, Lapeyre-Mestre M. Adverse drug reactions \& off-label drug use in pediatrics outpatients Br. J. Clin. Pharmacol., 2002;54(6):665-70.

J. Novotny, M. Novotny, Adverse drug reactions to antibiotics and major antibiotic drug interactions. Gen. Physiol. Biophys., 1999; 18: $126-139$

Jonville-Bera, Annie.Pierre. Jonville-Bera, Bruno. Giraudeau, Pascal. Blanc, Frederique. Beau-Salinas, Elisabeth. Autret-Leca Frequency of adverse drug reactions in children: a prospective study Br. J. Clin. Pharmacol., 2002; 53: 207-210

Jimmy Jose, G.M. Rao Padma, Beena Jimmy. Adverse drug reactions to fluoroquinolone antibiotics - analysis of reports received in a tertiary care hospital. Int. J. Risk Saf. Med., 2008; 20: 169-180.

Kavita Dhar, Shalu Chauhan, Jyotsna Sharma, Preeti Gaur, V.S. Chopra, Umakant Bajaj. To monitor the adverse drug reactions and safety of medicines commonly prescribed at obstetrics and gynaecology unit in a tertiary care hospital. Indian J. Pharm. Biol. Res.2014; 2(3):112-119.
Munir Pirmohamed, Alasdair M. Brecken. Clinical reviewAdverse drug reaction. BMJ, 1998; 316 (25): 1295-1298.

Mohammed Misbah Hussain, Kundlik Girhepunje, Ranju Pal, Shahina Sugra Siddiqua. Incidence of adverse drug reactions in a tertiary care hospital: a systematic review and meta-analysis of prospective studies. Der Pharmacia Lettre, 2010;2(3): 358-368.

Oshikoya KA, Njokanma OF, Chukwura HA, and Ojo IO. Adverse drug reactions in Nigerian children Paediatr. Perinat. Drug Ther. 2007; 8:81-88

Suthar J.V1 and Desai S.V. A study of adverse cutaneous drug reactions in outdoor patients attending to skin \& V.D. Department of Shree Krishna Hospital, Karamsad .Int. J. Res. Pharm. Biomed. Sci., 2011; 2 (1):274-279.

Sang-HeumPark. Is Antibiotic resistance microorganism becoming a significant problem in acute cholangitis in Korea .Clin Endosc 2012;45:111-2.

Tünger O, Dinç G, Ozbakkaloglu B, Atman UC, Algün U. Evaluation of rational antibiotic use. Int J Antimicrob Agents 2000; 15: 131-5.

The use of the WHO-UMC system for standardised case causality assessment. Available at :http://www.WHO-UMC.org/ graphics/4409.pdf [Accessed on $8^{\text {th }}$ October 2014]

\section{How to cite this article:}

Dhar K., Sinha A., Gaur P., Goel R., Chopra V. S., Bajaj U. Pattern of adverse drug reactions to antibiotics commonly prescribed in department of medicine and pediatricss in a tertiary care teaching hospital, Ghaziabad. J App Pharm Sci, 2015; 5 (04): 078-082. 